\title{
Changes in the concentration of specific amino acids in the serum of experimentally malnourished pigs
}

\author{
By R. F. GRIMBLE AND R. G. WHITEHEAD \\ MRC Child Nutrition Research Unit, PO Box 7051, Kampala, Uganda
}

(Received 20 October I969-Accepted 6 November 1969)

\begin{abstract}
I. The concentrations of individual free serum amino acids have been studied during the course of chronic protein malnutrition in experimentally malnourished pigs.

2. Until growth was markedly impaired, reducing the protein content of the diet had no significant effect on serum amino acid composition.

3. During the period when growth had practically ceased but kcal intake per kg body-weight was normal the concentrations of valine, leucine, isoleucine, threonine and eventually tyrosine fell, the levels of alanine and serine were above control levels and aspartic acid, glycine, methionine, phenylalanine, proline, arginine, histidine and lysine remained unaltered.

4. When the kcal intake per $\mathrm{kg}$ fell below control levels, owing to anorexia, and the animals began to lose weight, the levels of alanine, glycine, serine and methionine fell and valine, leucine, isoleucine, threonine and tyrosine remained well below control levels.

5. The physiological, nutritional and metabolic significance of these findings is considered. The changes in alanine and glycine concentration are discussed in terms of the regulation of gluconeogenesis. The reduction of the branched-chain amino acids is interpreted on the basis of their availability for synthetic and catabolic needs.
\end{abstract}

In a previous paper, Grimble \& Whitehead (1969) described changes in the serum amino acid ratio (Whitehead, $\mathrm{I}_{964} a$ ) at different stages in the development of primary protein malnutrition in young pigs; that paper should be read in conjunction with the work here published. It was found that the amino acid ratio only started to rise when the diet was so poor that growth had practically ceased and total serum protein and albumin concentration began to fall. Furthermore, after this time, the magnitude of the ratio was statistically correlated with rate of growth, appetite, serum protein and albumin concentration and hydroxyproline excretion. The results were interpreted as showing that the development of a distorted pattern of amino acids in the serum was of pathological significance in that the abnormality began at a time when the animal was clearly being adversely affected by the diet.

It is important to establish the metabolic cause of these changes in the serum amino acid pattern and this requires a knowledge of the time sequence for the development of abnormalities among the different amino acids. Holt, Snyderman, Norton, Roitman $\&$ Finch $(1963)$ attempted to obtain this information by studying the amino acid patterns in the serum of sixty-four children with severe kwashiorkor selected from various parts of the world. It was not possible to grade the children on clinical grounds and they had to be subdivided according to the degree of depression of the concentration of seven essential amino acids plus tyrosine. In apparently milder grades, plasma levels of most of the non-essential amino acids were raised whilst the most abrupt decreases seemed to occur in the levels of the branched-chain amino acids and tyrosine in particular. Although illuminating, the grouping of analytical results in this way does not really enable one to describe the progressive changes which occur with 
increasingly severe malnutrition since all the children had clinically demonstrable kwashiorkor.

Other approaches to this problem have involved feeding low-protein or protein-free diets to human subjects, but naturally these experiments could be of short duration only. Arroyave (1962) studied children whilst Swendseid, Tuttle, Figueroa, Mulcare, Clark \& Massey (1966) and Young \& Scrimshaw (1968) worked with adults. These authors all found that alanine was increased markedly during the early stages of protein deprivation, an abnormality more marked than the fall in the branched-chain amino acids.

The advantage of the pig model (Grimble $\&$ Whitehead, I969) was that the dietary deprivation could be investigated serially and continued until the animals died of malnutrition. The aim of the present experiment was to study changes in the concentration of specific amino acids at different phases during the development of malnutrition.

\section{MATERIAL AND METHODS}

\section{Animals}

The pigs used in this experiment were Large White stock and came from two litters. There were five control animals, four sows and one boar, and six animals, three boars and three sows, were placed on the series of low-protein diets.

Full details of the diets fed to these animals have already been described in a previous communication (Grimble \& Whitehead, 1969). Essentially the low-protein diets were prepared from a mixture of Amvilac no. I (Glaxo Research Ltd, Greenford, Middx), a cereal mixture and sucrose, but the relative amounts of the three components were varied to produce diets ranging from 25 to $2 \cdot 2 \%$ protein content. The control animals were fed diets containing initially $25 \%$ protein followed by another with $2 \mathrm{x} \cdot \mathrm{I} \%$ protein when the pigs reached 8 weeks of age. The control and low-protein diets were eaten ad lib.

\section{Procedure}

Blood was collected by venepuncture from pigs who had been fasted overnight. The serum was separated, then deep-frozen until analysed.

The serum amino acids were analysed in the TSM r AutoAnalyzer (Technicon Ltd, Chertsey) as modified for use with serum (R. F. Grimble \& R. G. Whitehead, in preparation); this method requires only $200 \mu \mathrm{l}$ of sample. The TSM I is a fully automated two column chromatographic system using very fine particle cation exchange resins (type A chromo-beads). Serum samples diluted with a $\mathrm{pH}$ I buffer containing $0.3 \mathrm{~N}$-lithium hydroxide and $0.05 \mathrm{M}$-citric acid, were applied, without prior deproteinization, to cartridges containing a special resin (type $\mathrm{C}_{4}$ ) with a high absorption capacity. These cartridges were fitted automatically to the tops of the columns at the beginning of each complete analytical cycle which lasted $5.5 \mathrm{~h}$. The amino acids quantitated were aspartic acid, threonine, serine, glycine, alanine, valine, methionine, isoleucine, leucine, tyrosine, phenylalanine, lysine, histidine, arginine and proline. Although glutamine and glutamic acid were separated during the chromatographic analytical procedure values for them are not reported since the 
former compound decomposes whilst standing in the resin cartridge before analysis. This in turn leads to an increase in the glutamic acid peak (R. F. Grimble \& R. G. Whitehead, in preparation). Accurate cystine values cannot be obtained from stored serum samples (Holt et al. 1963) and again these are not recorded here.

\section{RESULTS}

The growth pattern of the protein-deficient animals in this experiment has already been described (Grimble \& Whitehead, 1969). The rate of growth in weight only became significantly lower than that of the controls from week ro and it was not until week 16 that growth ceased; after week 20 the animals started to lose weight. Part of the reason for these growth changes probably lay in the calorie intake. The protein ingested per $\mathrm{kg}$ fell progressively during the experiment, but the kcal intake per $\mathrm{kg}$ body-weight was higher than in the control animals until week $\mathrm{x}_{4}$ and did not fall significantly below control levels until after week 20 . These facts have been repeated since they appear to have an important bearing on the subsequent changes in concentration of the serum amino acids.

Table I records values for the sum of fifteen free amino acids at the different stages of the experiment. Whilst the values in the protein-deficient pigs tended to be slightly lower than those of the controls from week 14 onwards, this difference did not become significant until week 26. The values have been further subdivided into the seven non-essential amino acids, aspartic acid, serine, glycine, alanine, histidine, arginine and proline, and seven essential ones, threonine, valine, methionine, isoleucine, leucine, lysine and phenylalanine plus tyrosine. The behaviour of the two groups was entirely different. The concentration of the essential amino acids in the low-protein animals fell markedly at week $\mathrm{I} 4$ and remained low for the remainder of the experiment whilst the levels of the non-essential amino acids tended to be higher than the control values except at the very end.

The concentrations of some individual amino acids are given in Table 2. Not all the amino acids measured have been recorded, only those in which significant differences were detected between the serum of the control and of the protein-malnourished pigs. The little-affected amino acids were aspartic acid, phenylalanine, lysine, histidine and arginine. The values for the normal animals showed only slight variation throughout the period of study, except for a tendency for certain of the essential amino acids to increase slightly in concentration, for example valine, and for the levels of some of the non-essential ones, such as serine and glycine, to fall. Although these changes were not statistically significant, they no doubt led to the slight fall in the amino acid ratio previously described (Grimble \& Whitehead, r969). In general the concentrations of amino acids were rather higher than those found in man. This fact had been obvious from the studies using the paper screening technique. Variations in the individual amino acid concentrations were relatively small although occasionally unexpected high values for a particular amino acid were found. This led, for example, to the large standard error for alanine in the serum of the control pigs in week 20.

The amino acid concentrations in the protein-deficient pigs behaved in a quite 


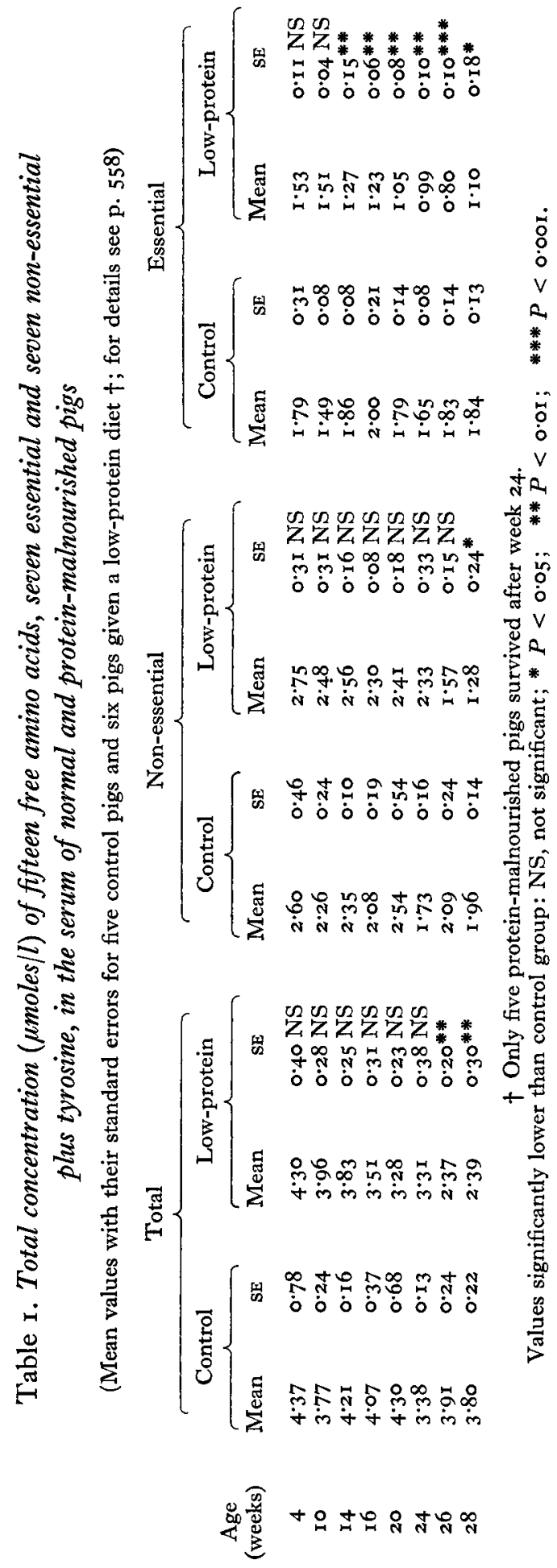




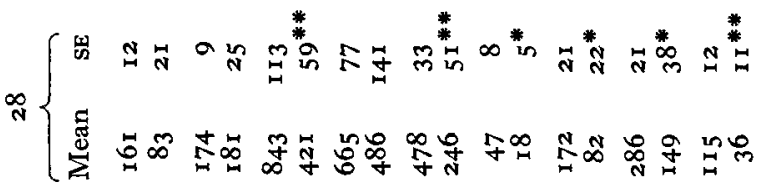

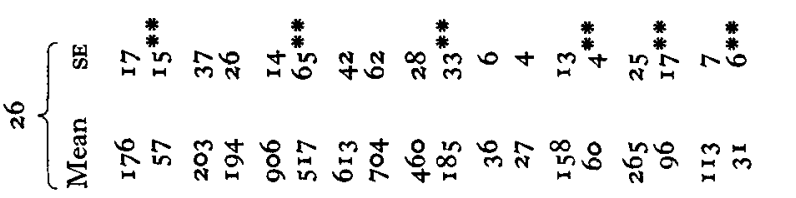

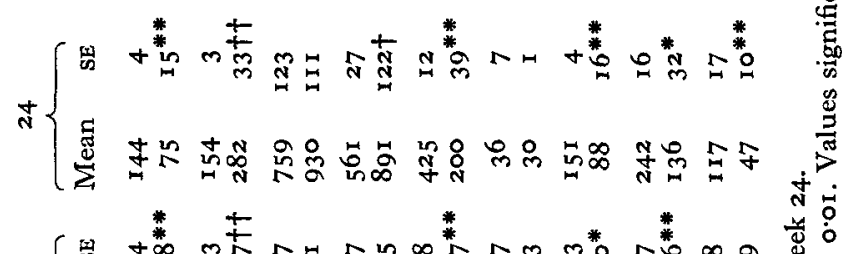

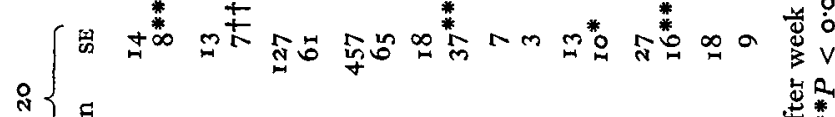

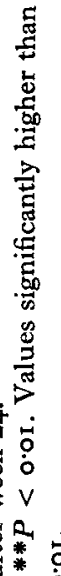

总家

(ख)

is

इ

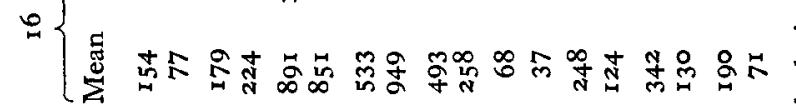

के $v$

क

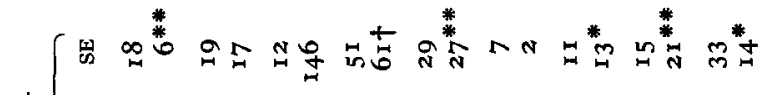

$\pm\{$

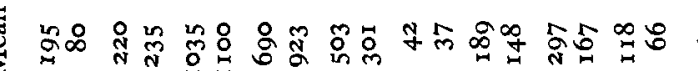


different manner from those in the controls, and these changes are conveniently separated into three stages: phase A, up to and including week ro when the amino acid concentrations in the two groups were not statistically different; phase $B$, from week $\mathbf{2} 2$ to week 24, during which time the concentrations of valine, methionine, isoleucine, leucine, threonine and eventually tyrosine fell significantly to levels below those of the controls and the concentrations of alanine and serine were above those of the controls; and phase $\mathrm{C}$ when there was a fall in the non-essential amino acids as well, glycine and tyrosine to below control levels and serine and alanine back to normal from their previously elevated concentrations. Also the concentration of the branched-chain amino acids tended to increase slightly during this final phase.

\section{DISCUSSION}

The use of a more sophisticated analytical procedure for measuring the changes in the serum amino acid pattern caused by primary protein malnutrition has confirmed the impression gained from the paper chromatographic analysis of the amino acid ratio. It is apparent that major changes did not occur until growth was severely affected. The results also demonstrated that, whilst the elevation of the amino acid ratio was mainly due to a reduction in the concentration of the branched-chain amino acids, a contributory factor during phase $B$, when energy intake was normal or above normal for the size of animal, was an increase in serine. The finding of elevated levels of serine and particularly alanine in this early phase, confirmed the studies of previous workers (Holt et al. 1963; Arroyave, 1962; Young \& Scrimshaw, 1968) but clearly an adequate energy intake is necessary for this abnormality to be observed.

The fall in concentration of serine, glycine, alanine and tyrosine in weeks 26 and 28 explains why the amino acid ratio fell to more normal levels in these serum samples (Grimble \& Whitehead, I969). This finding is of some practical importance since it probably confirms why at least two groups of workers (McLaren, Kamel \& Ayyoub, r965; Truswell, Wannenburg, Wittmann \& Hansen, 1966) failed to find elevated amino acid ratios in unequivocal cases of severe kwashiorkor. Both groups of workers commented on the fact that acute calorie deprivation due to diarrhoea and vomiting had been a feature of the clinical history of their subjects. These children presumably corresponded to phase $\mathrm{C}$ in the animal experiment. Low rather than normal or high levels of serum alanine have been a consistent finding in severe kwashiorkor in different parts of the world, whilst children living on the type of diet which produces kwashiorkor, but not yet exhibiting any pathological signs of malnutrition, exhibit high alanine levels (R. F. Grimble \& R. G. Whitehead, unpublished results). These facts indicate that total calorie deprivation is an eventual feature of severe kwashiorkor in most countries, although in Uganda it would seem that the problem is not as acute as in Cape Town or the Middle East.

These involved concentration changes among the different amino acids suggest the complexity of the derangements in intermediary metabolism underlying them. Two main questions need to be answered. (I) Of the essential amino acids measured, why were the concentrations of valine, leucine, isoleucine and threonine so markedly 
reduced whilst methionine, phenylalanine and lysine were much less affected? (2) What is the nature and significance of the mechanism which caused the levels of serine and particularly alanine to be raised above control levels on the low-protein, highcalorie diet whilst total calorie intake remained adequate but which resulted in their fall in concentration when the animals became severely anorexic?

The initial rise in some of the non-essential amino acids could be interpreted as an attempt by the body to balance the fall in the essential amino acids. The stability of the 'total free amino acid' concentration during this period shows how effective this mechanism might be. However, there is little direct evidence to suggest that precise maintenance of serum $\alpha$-amino nitrogen content has any homoeostatic importance. Also this idea does not explain the eventual fall in the concentration of alanine and glycine. A more plausible interpretation is offered by recent studies by Felig, Owen, Wahren \& Cahill (1969) who worked with adults subjected to prolonged starvation. These authors noted a pronounced fall in plasma alanine during the first io $\mathrm{d}$ without food after which time the alanine levels continued to fall but much less precipitously. It was demonstrated that the initial reduction in alanine was caused by a raised and preferential liver utilization of the amino acid during early starvation. The reason for this increased alanine utilization was explained on the grounds that it is a key amino acid in gluconeogenesis and serves as a direct source of glucose for brain metabolism until the latter organ has become adapted to keto-acid utilization (Owen, Morgan, Kemp, Sullivan, Herrera \& Cahill, I967). It was further claimed that maintenance of low alanine levels, in the subjects adapted to gluconeogenesis, eventually served to diminish alanine uptake by the liver because of partial substrate depletion thus minimizing protein catabolism. By similar reasoning it can be argued that the higher serum alanine levels found during phase B would indicate a minimal gluconeogenic activity, since the high carbohydrate content of the diet would remove the need for alanine utilization in glucose synthesis. Felig et al. (1969) also demonstrated that glycine utilization by the kidney was increased in starvation and this could explain the eventual fall in the concentration of this amino acid at the end of phase $\mathrm{C}$, in weeks 26 and 28 although a fall in serum glycine was not found in starving adults.

One can also speculate on the cause of the reduced serum levels of certain of the essential amino acids. Except during the post-prandial phase, the concentration of amino acids in the serum probably depends on the balance between availability and the demand imposed by maintenance requirements, growth and amino acid catabolism leading to urea synthesis. In phase A the protein eaten per $\mathrm{kg}$ fell from $7 \cdot 36$ to $\mathrm{r} \cdot 23 \mathrm{~g}$ before the concentrations of the branched-chain amino acids fell significantly. Presumably during this period, supply was always in excess of demand. In conditions in which protein intake was more limiting, in phases $\mathrm{B}$ and $\mathrm{C}$, then reduced serum values for these amino acids would be expected and in extreme cases the very low values found in severe kwashiorkor might be expected although these were not produced experimentally. In the absence of an adequate carbohydrate intake on a proteinrestricted diet, as in starvation, these changes were probably negated to some extent by the release of essential amino acids from the tissues. On a high-carbohydrate diet, 
however, the action of glucose, in stimulating insulin secretion, would reverse the direction of this 'homoeostatic' mechanism.

Why all the essential amino acids were not reduced in concentration is a further problem. Holt et al. ( 1963 ) considered that the relatively normal levels of histidine and phenylalanine in children with kwashiorkor could be explained by the abnormal catabolism demonstrated for these amino acids by Dean \& Whitehead (1963). Further work (Whitehead, I964b) suggested that lysine catabolism might also be affected and this could have been the reason for the little-changed lysine levels.

An alternative explanation is suggested by the work of Mimura, Yamada \& Swendseid (r968). These workers reported that a protein-free diet increased significantly the activity of the specific branched-chain amino acid transaminase. Furthermore, the tissue distribution of this enzyme was different from that of the other transaminases in that there was a higher activity in the muscle than in the liver. Muscle cells may also be less severely affected by malnutrition than the liver cells, which could lead to a preferential catabolism of the branched-chain amino acids. Whilst this might explain why the branched-chain amino acids were in low concentration, it does not provide an answer as to why threonine and tyrosine were equally affected.

Clearly there are many factors involved in the maintenance of normal serum amino acid patterns and the elucidation of these problems is of importance not only in the assessment of nutritional status but to our understanding of amino acid and protein homoeostasis.

The authors wish to thank Dr George F. Cahill Jr, of the Department of Medicine, Harvard University, for detailed personal discussion of his theories concerning the control of gluconeogenesis. We also acknowledge the technical assistance of $\mathrm{Mr} F$. Nkubihinda.

\section{REFERENCES}

Arroyave, G. (1962). Am. F. clin. Nutr. 1x, 447.

Dean, R. F. A. \& Whitehead, R. G. (1963). Lancet i, I 88.

Felig, P., Owen, O. E., Wahren, J. \& Cahill, G. F. Jr (1969). F. clin. Invest. 48, 584.

Grimble, R. F. \& Whitehead, R. G. (1969). Br. \%. Nutr. 23, 791.

Holt, L. E. Jr, Snyderman, S. E., Norton, P. M., Roitman, E. \& Finch, J. (1963). Lancet ii, 1343.

McLaren, D. S., Kamel, W. W. \& Ayyoub, N. (1965). Am. F. clin. Nutr. 17, 152.

Mimura, T., Yamada, C. \& Swendseid, M. E. (r968). F. Nutr. 95, 493.

Owen, O. E., Morgan, A. P., Kemp, H. G., Sullivan, J. M., Herrera, M. G. \& Cahill, G. F. Jr. (I967). F. clin. Invest. 46,1589 .

Swendseid, M. E., Tuttle, S. G., Figueroa, W. S., Mulcare, D., Clark, A. J. \& Massey, F. J. (1966). F. Nutr. 88, 239.

Truswell, A. S., Wannenburg, P., Wittmann, W. \& Hansen, J. D. L. (I966). Lancet i, r r6z.

Whitehead, R. G. (1964a). Lancet i, 250.

Whitehead, R. G. (1964b). Nature, Lond. 204, 389 .

Young, V. R. \& Scrimshaw, N. S. (I968). Br. F. Nutr. 22, 9. 